\title{
Optimal Geometric Allocation for Cost Management of Vehicle Maintenance
}

\author{
Amani M. Al Hadidi ${ }^{1, *}$, Rami A. Maher², Osama T Al Meanazel ${ }^{3}$ \\ ${ }^{1}$ Department of Allied Engineering Sciences, Faculty of Engineering, The Hashemite University, Zarqa, 13133, Jordan \\ ${ }^{2}$ Faculty of Engineering, Isra University, Amman, Jordan \\ ${ }^{3}$ Faculty of Engineering, The Hashemite University, Zarqa, 13133, Jordan
}

Received January 25, 2021; Revised April 2, 2021; Accepted April 18, 2021

\section{Cite This Paper in the following Citation Styles}

(a): [1] Amani M. Al Hadidi, Rami A. Maher, Osama T Al Meanazel, "Optimal Geometric Allocation for Cost Management of Vehicle Maintenance," Civil Engineering and Architecture, Vol. 9, No. 3, pp. 605-610, 2021. DOI: 10.13189/cea.2021.090304.

(b): Amani M. Al Hadidi, Rami A. Maher, Osama T Al Meanazel (2021). Optimal Geometric Allocation for Cost Management of Vehicle Maintenance. Civil Engineering and Architecture, 9(3), 605-610. DOI: 10.13189/cea.2021.090304.

Copyright@2021 by authors, all rights reserved. Authors agree that this article remains permanently open access under the terms of the Creative Commons Attribution License 4.0 International License

\begin{abstract}
The paper aims to find out the best plane location of a construction company headquarter for $n$ construction sites, and reducing the maintenance cost of the vehicles working between the headquarters and the sites to the lowest cost possible. The total traveled distance of all possible locations is calculated, by assuming each location in two ordinations $(x, y)$. MATLAB software is used to generate an accurate model and calculations of each point presenting a construction site. The results found different models of different cases of locations with a variety of coordination. The results showed that a programmed model can solve many problems related to cost management in construction sites for any given organization. The model was successfully used to lower (theoretically) the cost of the used vehicles from and into the location sites and the headquarter of the company. Accordingly, the company can conclude some cost-effective factors, which aid in deciding on the necessity of road quality pavement.
\end{abstract}

Keywords Nonlinear Optimization, Geometric Allocation, Maintenance Cost Management

\section{Introduction}

Project Management Software (PMS) has the target of providing a meaningful solution for all managerial processes of planning, execution, monitoring, controlling, evaluation, and decision making. The core mission of the PMS system emphasizes finding effective solutions that can face development and solve complex difficulties in large-scale projects easily and successfully $[1,2]$. Project Management Software systems give the result based on the software development process, which depends upon the project itself and the manager's needs. PMS model builds utilization software tools to solve different problems. Besides, the graphical user interface (GUI) is designed to simplify using these software packages [3]. This model clarifies the importance of the development software package for EPM problems. It explains, in detail, how the complex problems, which are difficult to solve traditionally, would be easy, simple, and quick to be solved by the software.

Geometric Allocation management is an important and non-conventional problem in Engineering Project Management (EPM). In practice, there are several real applications, in which the geometrical location of a place with respect to other places has to be determined such as to minimize the total distances from that place to the other places. For instance, the location of a refinery that supplies the fuel to some towns has to be determined to have a minimum length of transporting pipes [4]. When the raw materials have to be brought from different storages to one cargo point in minimum time, is another example. On the other hand, the problem of replacement of service vehicles depends on the maintenance cost, which is interns depending on the distances they travel annually $[5,6]$. The 
analysis location selection is performed for another application for finding the fish center using the Ahp statistical approach [7]. The maintenance cost compared to pavement cost could be included within the risk management assessment and budget calculation. In [8], it is shown that the risk management assessment strongly affects the cost budget.

In this paper, the problem of determining the optimal plane location of a construction company headquarters for $\mathrm{n}$ construction sites will be solved. The aim is to minimize the maintenance cost of the vehicles that are working between the headquarters and the sites. This aim can be achieved by finding the total traveled distance.

\section{The Management Problem Statement and Assumptions}

Consider a construction company takes a deal to construct industrial buildings in $n$-sites. The sites are located around an arterial road in a specified area; see Figure 1. In this area, there are no problems with properties and no other country-roads as well. The contract has to establish in $T$ years. One of the company preparations is to decide upon the location of the company headquarters in this area.

To fulfill other logistic operations, the company prefers to have the location of the headquarters near the arterial road (mathematically, a point satisfying the arterial road equation). Therefore, the manager excludes two cases, which assume that the headquarters position at the center-of-gravity point or at a point where the sum of distances to all sites is minimal. Furthermore, the manager should decide, upon the quality of the used roads, whether the pavement of the local roads is necessary or not. For the construction company, there may be several justifications as to why the company prefers paved roads, such as:

- The maintenance cost and usage of ordinary vehicles along the roads

- The maintenance cost and usage of heavy trucks and special equipment like cranes

- The cost of transporting the raw materials
The nearest to labor societies, water supplies, etc.

Primarily, the manager decides to consider the minimum maintenance and the usage costs, during one year, of ordinary vehicles that travel between the headquarters and sites as a criterion of the decision. He recognizes that the maintenance and vehicle usage depending upon the type of road, the traveling distance, and the traveling time. For this purpose, the manager collects the different assumed items as are recommended by the specialists, for instance, as given in Table 1. Furthermore, the manager knows that the average speed of vehicles on the arterial rood is $V_{1} \mathrm{~km} / \mathrm{h}$, whereas it is $V_{2} \mathrm{~km} / \mathrm{h}$ on a paved collector or $V_{3} \mathrm{~km} / \mathrm{h}$ on unpaved local roads. Finally, the manager assumes that vehicles will make one journey to sites per day, i.e., from the headquarters to sites and return. Then, the results of this primer solution can be modified to real situations that consider an average number of vehicles per day.

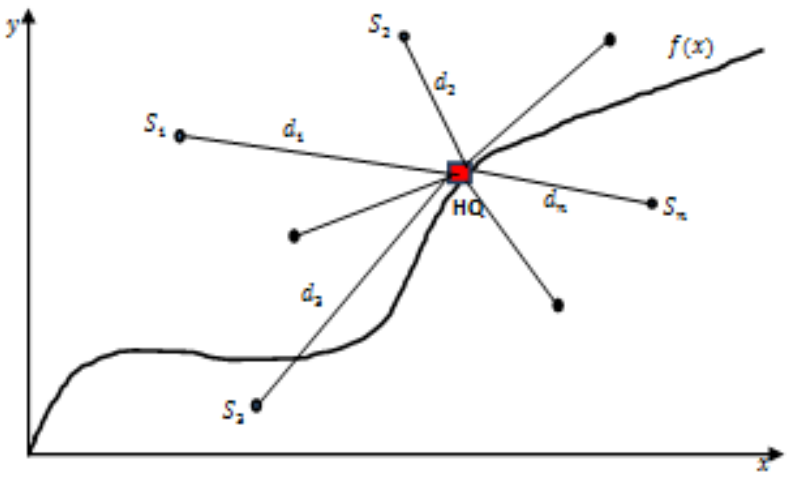

Figure 1. Headquarters near an arterial road

The manager realizes two cases to be considered for computing the minimum cost for one year. The computation in each case will be performed with two alternatives: traveling on paved roads and unpaved roads. The locations are assumed to be in two coordinates $(x, y)$ for easy implementation and computation of the problem. For the three coordinate systems, the problem can be solved similarly; however, it is more complicated, and the computation burden is huge.

Table 1. Collected items for vehicle maintenance cost management

\begin{tabular}{|c|c|c|c|c|c|c|}
\hline \multirow{2}{*}{$\begin{array}{c}\text { Types of } \\
\text { Roads }\end{array}$} & \multicolumn{2}{|c|}{ Maintenance } & \multirow{2}{*}{ Fuel cost $/ \mathrm{km}$} & \multicolumn{2}{|c|}{ Tires wear } & \multirow{2}{*}{ Oil cost $/ \mathrm{km}$} \\
\hline & cost/month & $\operatorname{cost} / 100 \mathrm{~km}$ & & cost $/$ month & $\operatorname{cost} / 100 \mathrm{~km}$ & \\
\hline $\begin{array}{c}\text { I: } V_{1} \\
90 \mathrm{~km} / \mathrm{h}\end{array}$ & \multirow{3}{*}{$\begin{array}{c}\text {-Lumps } \\
\text {-Battery } \\
\text {-Washing } \\
\text {-Cooling liquids } \\
\text {-Painting } \\
\text {-Chairs repair } \\
\text {-Miscellaneous }\end{array}$} & \multirow{3}{*}{$\begin{array}{c}\text {-Filters } \\
\text {-Electrical plugs } \\
\text {-Balance test } \\
\text {-Tires repair } \\
\text { - Miscellaneous }\end{array}$} & Liter $/ 10 \mathrm{~km}$ & 3 Years usage & $60000 \mathrm{~km}$ & \multirow{3}{*}{$\begin{array}{c}\text {-Engine } \\
\text {-Gears } \\
\text {-Lubrication } \\
\text {-power }\end{array}$} \\
\hline $\begin{array}{l}\text { II: } \quad V_{2} \\
60 \mathrm{~km} / \mathrm{h}\end{array}$ & & & Liter $/ 8 \mathrm{~km}$ & 2.5 Year usage & $50000 \mathrm{~km}$ & \\
\hline $\begin{array}{c}\text { III: } V_{3} \\
30 \mathrm{~km} / \mathrm{h}\end{array}$ & & & Liter/6 km & 2 Year usage & $40000 \mathrm{~km}$ & \\
\hline
\end{tabular}




\section{Geometric Allocation Problem Model}

The location of the headquarters is assumed to be near the arterial road at a point such to minimize also the total traveled distance between the headquarter and their construction sites, as shown in figure 1. This assumption is conducted from the managerial rules found in companies' documentations. Traditionally, the approximate location of the headquarter is the center of gravity point in the considered area, i.e. to average the $x$ and $y$ coordinates of all sites and then to lock for the nearest point on the arterial road. However, such a solution causes unsatisfactory maintenance cost management, and hence rigid modeling of the problem is required. Therefore, in what follows, a nonlinear optimization model is invoked.

Mathematically, it is a nonlinearly constrained optimization problem, i.e.

$$
\begin{array}{cr}
d_{\text {total }}= \\
\min _{x, y, \epsilon, \pi}\left\{\sum_{i=1}^{n}\left[\sqrt{\left(x_{s i}-x_{h d}\right)^{2}+\left(y_{s i}-y_{h d}\right)^{2}}\right]\right\}, & i= \\
1,2 \ldots n & \\
\text { Subjected to: } y_{h d}-f\left(x_{h d}\right)=0 \Rightarrow & y_{h d}- \\
\sum_{i=0}^{m} c_{m-i} x_{h d}{ }^{m-i}=0 & \text { (2) } \\
x_{h d} \leq \mathrm{XAMP}, \quad y_{h d} \leq \text { YAMP }
\end{array}
$$

where $x_{h d}$ and $y_{h d}$ are the coordinates of the headquarters, $x_{s i}$ and $y_{s i}$ are the coordinates of the $i^{\text {th }}$ site, and XAMP and YAMP are the coordinates of the considered area. The arterial road is represented by a polynomial of $m$ degree; the polynomial coefficients are $c_{i}$. These coefficients can be found by the usual data fitting procedure after selecting a suitable polynomial degree. The necessary data can be obtained from the area map.

The objective is the total distance to be minimized. Consequently, the total annual traveling distance is given by

$$
D=2 N_{w d} d_{\text {total }}
$$

where $N_{w d}$ is the number of working days per year. The total time of travel on paved and unpaved roads will be given simply by (for the definition of the speed on each type of roads, see table 1)

$$
T 1=\left\{\begin{array}{cc}
\frac{D}{V 3} ; & \text { unpaved roads } \\
\frac{D}{V 2} ; & \text { paved roads }
\end{array}\right.
$$

To take the advantage of the main road, the manager thinks, as a second alternative, to pave the shortest distance from each site to the arterial road before the vehicles travel on the arterial road to the headquarters. To minimize the travel on the arterial road, the headquarters must be located at a point that divides the number of intersection points, as shown in figure 2.Therefore two cases will be considered; when the number of sites is odd or even. The shortest (normal) distances from the sites to the arterial road are calculated in three steps as follows:

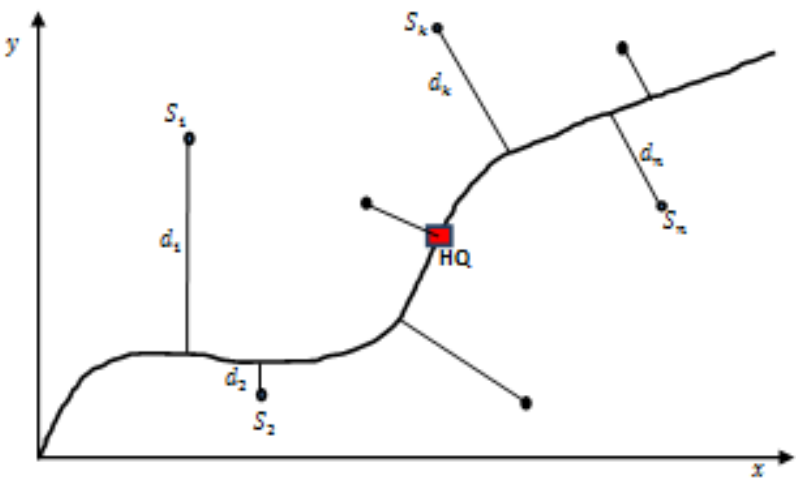

Figure 2. Shortest distances between sites and arterial road

\section{Step 1:}

Solve the nonlinear equation for each site:

$$
\left(x-x_{s i}\right)+\left[f(x)-y_{s i}\right] f^{\prime}(x)=0 ; i=1,2 \ldots n
$$

Or,

$$
\begin{gathered}
\left(x-x_{s i}\right)+\left[\sum_{i=0}^{m} c_{m-i} x_{h d}^{m-i}-y_{s i}\right] \sum_{i=0}^{m} c_{m-i}(m- \\
i) x_{h d}{ }^{m-i-1}=0
\end{gathered}
$$

The real positive roots $x_{\text {real }, j}, j=1,2 \ldots$ from the total $(2 m-1)$ roots are collected for each site.

\section{Step2:}

For each real positive root $x_{\text {real }}$, we compute the corresponding $y_{\text {real }}$ using the arterial road equation. Then the distances from the $i^{\text {th }}$ site to each point $\left(x_{\text {real }}, y_{\text {real }}\right)$ are computed from

$$
d_{i, j}=\sqrt{\left(x_{s i}-x_{\text {real }, j}\right)^{2}+\left(y_{s i}-y_{\text {real }, j}\right)^{2}}, j=1,2 \ldots
$$

Therefore, the normal distance from the $i^{\text {th }}$ site to the arterial road is the minimum of $d_{i, j}$ i.e.

$$
d_{\text {norm }, i}=\min _{j=1,2}\left\{d_{i, j}\right\}, i=1,2 \ldots n
$$

Consequently, next, the corresponding intersection points are denoted $\left(x_{i n t, i}, y_{\text {int }, i}\right)$.

\section{Step 3:}

The intersection points are arranged in an ascendant way with respect to the $x$-axis, i.e., renaming the number of the sites correspondingly; see figure (2). The headquarters have to be located at the center ascendant intersection point, $\operatorname{say}\left(x_{H Q}, y_{H Q}\right)$, to reach the headquarters along the arterial road from any of the intersection points such as to have minimum total traveling distances. Note that if $n$ is an odd number then the center ascendant intersection point is numbered as $(n+1) / 2$ and if $n$ is even then it is 
numbered as $n / 2$.

The distance traveled on the arterial road $d_{a r}$ is calculated as the distance of the arc on a curve. Thus, the distance from an $i$ th point $\left(x_{i n t, i}, f\left(x_{i n t, i}\right)\right)$ to the headquarters is given by [7]

$$
\begin{gathered}
d_{a r, i}=\int d s=\int_{x=x_{i n t, i}}^{x=x_{H Q}}\left(\sqrt{1+\left(\frac{d y}{d x}\right)^{2}}\right) d x, x_{H Q}>x_{i n t, i} \\
d_{a r, i}=\int d s=\int_{x=x_{H Q}}^{x=x_{i n t, i}}\left(\sqrt{1+\left(\frac{d y}{d x}\right)^{2}}\right) d x, x_{H Q}<x_{i n t, i}
\end{gathered}
$$

where the derivative $(d y / d x)$ is the derivative of the arterial road equation.

The total distance of the roads that are connecting the headquarters to the sites, is given by the sum of the two items of distances,

$$
D_{\text {Total }}=D_{1}+D_{2}=\sum_{\mathrm{i}=1}^{\mathrm{n}} d_{\text {norm }, i}+\sum_{\mathrm{i}=1}^{\mathrm{n}} d_{\text {ar }, i}
$$

Similarly, in this option, the total traveling distance is given by $\left(2 N_{w d} D_{\text {total }}\right)$. The total annual traveling time will be simply given by

$$
T_{n r}=2 N_{w d}\left\{\begin{array}{lc}
\frac{D_{2}}{V_{3}}+\frac{D_{1}}{V_{1}}, & \text { unpaved roads } \\
\frac{D_{2}}{V_{2}}+\frac{D_{1}}{V_{1}}, & \text { paved roads }
\end{array}\right.
$$

For such a nonlinear optimization problem, the MATLAB toolboxes can be efficiently used to write a program that interacts with graphical interface user (GIU) to select the desired case (the number of sites, the equation of the arterial road, and the option and alternative) and solve the problem. The mathematical model in equations $1-10$, considering the maintenance items given in table 1 , will be used with four options. These options are the paved and unpaved direct optimal distance model as in figure (1) and similarly paved and unpaved optimal distance as in the second alternative shown in figure (2). According to the obtained results, the manager has to decide which option and alternative should be selected.

\section{Numerical Results}

In this section, the solution of the nonlinear problem for finding the headquarters position near the arterial road in any of the two considered options is obtained. Furthermore, to decide between the alternatives (paved or unpaved roads), field data of the maintenance cost are assumed as in table 2 . The value 1 is assigned to the price of one liter of fuel per one kilometer (unit-price UP), and all other cost items are referred to that UP. For simulation, 1 vehicle per 1 site, and 300 working days per one year (25 days each month) are assumed.

Two cases are considered as shown in table 3 . The first case considers an odd number of sites and a specific polynomial of the arterial road curve. Four sites are located above the road and three are located below the road. The optimized solutions (the total traveling distances) for both alternatives give two different headquarter positions at the road. For the second case, 10 sites are distributed around the considered arterial road (five sites above and below). Similarly, the optimized solutions for the two alternatives are obtained.

Four parameters are selected to perform the comparison between four possible outputs that can be used for decision-making. The distance traveled to reach headquarter for the first alternative or to reach the arterial road for the second alternatives is denotedTRD. The corresponding total annual (two-way) distance is denoted TD. For all possible choices, the total time of travel, and total cost are TT and TC, respectively. Note that, for the second alternative, the total distance consists of two parts,

\begin{tabular}{|c|c|c|c|c|c|c|}
\hline & \multicolumn{2}{|c|}{ Maintenance } & \multirow[b]{2}{*}{$\begin{array}{l}\text { Fuel cost } / \mathrm{km} \\
\text { (UP) }\end{array}$} & \multicolumn{2}{|c|}{ Tires wear } & \multirow{2}{*}{$\begin{array}{l}\text { Oil cost } \\
/ \mathrm{km} \\
\text { (UP) }\end{array}$} \\
\hline & $\begin{array}{c}\text { Cost/month } \\
\text { (UP) }\end{array}$ & $\begin{array}{c}\text { Cost } / 100 \mathrm{~km} \\
\text { (UP) }\end{array}$ & & $\begin{array}{c}\text { Cost/ } \\
\text { Month } \\
\text { (UP) }\end{array}$ & $\begin{array}{c}\text { Cost/ } \\
100 \mathrm{~km} \\
\text { (UP) }\end{array}$ & \\
\hline I: $\quad V_{1}=90 \mathrm{~km} / \mathrm{h}$ & 84 & 12.6 & 1 & 83 & 3.33 & 0.125 \\
\hline II: $\quad V_{2}=60 \mathrm{~km} / \mathrm{h}$ & 84 & 13.5 & 1.15 & 100 & 4.5 & 0.25 \\
\hline III: $V_{3}=40 \mathrm{~km} / \mathrm{h}$ & 94 & 17 & 1.55 & 300 & 5.5 & 2 \\
\hline
\end{tabular}
the summation of the shortest distances and the summation of the distances on the arterial road (not shown in table 3).

Table 2. Field data for Maintenance Cost of Different Items 
Table 3. The two considered cases and their results

\begin{tabular}{|c|c|c|c|c|}
\hline \multicolumn{5}{|c|}{ CASE I: 7 Sites } \\
\hline \multicolumn{5}{|c|}{ 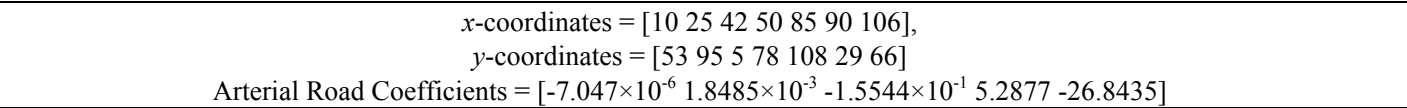 } \\
\hline & \multicolumn{2}{|c|}{$\begin{array}{c}\text { Alternative } 1 \\
\text { Figure } 1\end{array}$} & \multicolumn{2}{|c|}{$\begin{array}{c}\text { Alternative } 2 \\
\text { Figure } 2\end{array}$} \\
\hline & Unpaved as in & Paved as in & Unpaved as in & Paved as in \\
\hline TRD $(\mathrm{km})$ & \multicolumn{2}{|c|}{342.5} & \multicolumn{2}{|c|}{216.1} \\
\hline $\mathrm{TD}(\mathrm{km})$ & \multicolumn{2}{|c|}{205500} & \multicolumn{2}{|c|}{262980} \\
\hline TT (hours) & 5137.5 & 3425 & 4722.9 & 3642.4 \\
\hline TC (UP) & 77914 & 32574 & 66323 & 37717 \\
\hline \multicolumn{5}{|c|}{$\begin{array}{l}\text { Headquarters Coordinates Solution: } \\
\text { Option 1: (42.4941,36.0394), } \\
\text { Option 2: (70.6484,47.1809) } \\
\end{array}$} \\
\hline \multicolumn{5}{|c|}{ CASE II: 10 Sites } \\
\hline \multicolumn{5}{|c|}{ 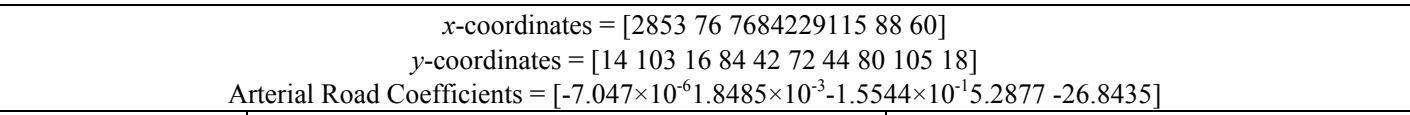 } \\
\hline TRD $(\mathrm{km})$ & \multicolumn{2}{|c|}{458.7} & \multicolumn{2}{|c|}{229.7} \\
\hline $\mathrm{TD}(\mathrm{km})$ & \multicolumn{2}{|c|}{275210} & \multicolumn{2}{|c|}{357990} \\
\hline TT (hours) & 6880 & 4587 & 5892 & 4743 \\
\hline TC (UP) & 104340 & 43623 & 80600 & 50190 \\
\hline \multicolumn{5}{|c|}{$\begin{array}{l}\text { Headquarters Coordinates Solution: } \\
\text { Option 1: }(70.9578,47.5127) \\
\text { Option 2: }(61.7469,39.7684)\end{array}$} \\
\hline
\end{tabular}

From table 3, it can be noted that the solutions are obtained irrespective of the number of sites or their distribution, i.e., the used software can handle the different inputs around the same arterial road. For both cases, a clear decision is to go with a paved-first alternative because of the lowest cost of vehicle maintenance (32574 and 43623 UP). However, if paved roads are preferred, then going with the second alternative may be the cheapest alternative due to the high cost of pavement. This because the second alternative offers a smaller distance summation (216.1 and $229.7 \mathrm{Km}$ compared to 342.5 and $458.7 \mathrm{Km}$, respectively), and takes the advantage of the paved arterial road. For instance, in the second case, the difference $(50190-43623$ $=6.567 \mathrm{UP})$ gives $(14.3 \mathrm{UP} / \mathrm{Km})$ paving cost, which is certainly unbelievable. Besides, for the paved second alternative, the increment of time will be a fraction of an hour. Moreover, for the unpaved roads, the lower costs (66323 and 80600 compared to 77914 and 104340) suit also the second alternative. Therefore, for the considered two cases, the right decision is to go with the paved second alternative.

\section{Conclusions}

The work herein represents a part of developing a software assessment for engineering project management in the construction industry. In this important social sector, problems are so many ranging from the standard usual scheduling and material transportation problem to nonstandard including the maintenance of the service vehicles and trucks and labor distribution problems. One such problem is the determination of the optimal geometric location of the company headquarter that manages and controls at the same time several construction sites. The significance of solving such a problem is at least twofold. The first is to minimize the cost of maintenance of the used vehicles by minimizing the annual traveled distance and consequently the vehicle working time. The second is to maximize the fluent flow of the working orders.

Due to the problem complexity, the two-dimension geometric case is considered with two alternatives for connecting the headquarter to the sites. Besides, it is assumed that the paved arterial road is modeled by a $4^{\text {th }}$-order polynomial and no further geometric constraints exist. For both alternatives, the paved and unpaved roads are considered. The cost data of maintenance items are based on domestic prices.

The solution of the nonlinear optimization problem is obtained for an odd and even number of sites to conclude the minimal annual distance, traveling time, and minimum maintenance cost. For the considered data, the minimum cost is found with direct connecting and paved roads. On the other hand, when the company has to consider the cost of paving the roads (the direct with first alternative and the shortest with the second alternative), then it could go with the second alternative because of the high cost of paving. Moreover, if the company decides to use unpaved roads 
then the minimum cost will be with the second alternative. Therefore, a central conclusion is that an effective decision depends on several parameters, and hence the need for an instantaneous interface with such a solution algorithm becomes obvious. The MATLAB GUI tool represents a solution option.

\section{REFERENCES}

[1] Bierman, H., C.P. Bonini, and W.H. Hausman, "Quantitative Analysis for Business Decisions", Richard D. Irwin, Inc., Homewood, IL, 1977)pp. 642

[2] Dykstra, D.P. "Mathematical Programming for Natural Resource Management", McGraw-Hill, Inc., New York, 1984).318 pp.

[3] Hillier, F.S., and G.J. Lieberman, "Introduction to Operations Research", sixth edition (McGraw-Hill, Inc.,
New York, 1995), pp. 998

[4] Ignizio, J.P., J.N.D. Gupta, and G. R. McNichols, "Operations Research in Decision Making”, Crane, Russak\& Company, Inc., New York, 1975, pp. 343

[5] Lapin, L. L. Quantitative Methods for Business Decisions with Cases, third edition (Harcourt Brace, Jovanovich, Publishers, San Diego, 1985), pp. 780

[6] Ravindran, A., D.T. Phillips, and J .J. Solberg "Operations Research: Principles and Practice", second edition (John Wiley\& Sons, New York, 1987),pp. 637

[7] Verani Hartati, Fharidaty Aprillia Islamiati, "Analysis of Location Selection of Fish Collection Center Using Ahp Method in National Fish Logistic System", Civil Engineering and Architecture 7(3A), 2019, pp. 41-49. DOI: 10.13189/cea.2019.071307

[8] Jarosław Konior, "Mitigation of Correlated Risk in Construction Projects", Civil Engineering and Architecture 7(1): 2019, pp. 17-22. DOI: 10.13189/cea.2019.070103 